Short Communication

\title{
Electrochemical Impedance Spectroscopy Study on Hydration Feature of Calcium Sulfoaluminate Cements
}

\author{
Qiancheng Fang, Shang $\mathrm{Li}^{*}$ \\ Institute of Architecture Engineering, Huanghuai University, 463000, China \\ "E-mail: fangqiancheng314@yeah.net
}

doi: $10.20964 / 2019.06 .54$

Received: 2 February 2019 / Accepted: 5 April 2019 / Published: 10 May 2019

\begin{abstract}
Electrochemical impedance spectroscopy (EIS) was used to study the hydration procedure of calcium sulfoaluminate (CSA) cements as a nondestructive testing method. The CSA cements were prepared by mixing the CSA clinker with commercial micronized natural gypsum. The compressive strength evolution of mortars prepared from gypsum pastes indicates that the results are in perfect agreement with the formation of the ettringite. The experimental results indicate that the EIS behavior of CSA cements was varied with the hydration process and increasing hydration time, as the resistance of ion transport processes $\left(\mathrm{R}_{\mathrm{CT}}\right)$ gradually increased. Furthermore, the $\mathrm{R}_{\mathrm{CT}}$ and semicircle Nyquist curve in highfrequency reduces gradually by increasing the water cement ratio. The curve of impedance spectrum move to the right by increasing gypsum content in cement paste resulting in the increase of $\mathrm{R}_{\mathrm{CT} 1}$ with gypsum concentration increasing. The experimental findings show that EIS method is an appropriate technique for evaluation of the hydration feature of CSA cements.
\end{abstract}

Keywords: Calcium sulfoaluminate cements; Electrochemical impedance spectroscopy; Gypsum contents; Water cement (w/c) ratio; Hydration process

\section{$\underline{\text { FULL TEXT }}$}

(C) 2019 The Authors. Published by ESG (www.electrochemsci.org). This article is an open access article distributed under the terms and conditions of the Creative Commons Attribution license (http://creativecommons.org/licenses/by/4.0/). 